\title{
Review
}

\section{TIPSS 10 years on}

The transjugular intrahepatic portosystemic stent-shunt (TIPSS) has been a clinical reality for the past 10 years. The procedure is essentially a side-to-side $\mathrm{H}$ graft portosystemic shunt, with the expandable metallic stent being the $\mathrm{H}$ graft. Over this time, TIPSS has been put through the paces of assessment of technical feasibility, pilot studies through to randomised clinical trials looking at treatment of complications of portal hypertension. Following its introduction, there was an enthusiastic welcome for this procedure which was seen as an attractive alternative to shunt surgery - it did not require general anaesthesia (most of the time) or a laparotomy, and was applicable to many patients with severe liver disease unsuitable for surgery. Treatment of variceal haemorrhage, ascites, hepatic hydrothorax, hepatorenal syndrome, and Budd-Chiari syndrome using TIPSS has been studied. The initial enthusiasm was subsequently tempered by reports from these studies of shortcomings of TIPSS, namely the inevitable development of shunt stenosis and increased incidence of hepatic encephalopathy. In the light of the available evidence, what is the place of TIPSS in current clinical practice?

\section{Indications}

The first application of TIPSS was in the treatment of variceal haemorrhage, and this remains the main indication for TIPSS. The prevention of rebleeding from oesophageal varices has been the area studied most intensely. There are so far eight prospective randomised clinical trials ${ }^{1-8}$ comparing TIPSS with endoscopic treatment published as papers and three ${ }^{9-11}$ published as abstracts (table 1). A meta-analysis ${ }^{12}$ of these studies has also been published recently. The ensuing discussion will be based on the eight papers as many aspects of the discussion require information not available from the abstracts. In all but one study, bleeding rates were reduced from $35-50 \%$ to $10-25 \%$. In the first seven studies, differences in mortality between the treatment groups were not shown. These studies were designed to look at rebleeding as the primary end point and mortality as a secondary end point. There was the inevitable statistical problem of insufficient numbers to demonstrate mortality differences as well as the ethical consideration of allowing failures of endoscopy to be rescued by TIPSS, a feature that would hide potential mortality differences. The most recent study, ${ }^{8}$ published in 1999, did not have a TIPSS rescue arm. This study reported improvement for both rebleeding and survival with TIPSS compared with sclerotherapy. On the issue of costs, studies from both sides of the Atlantic looking at direct costs showed TIPSS to be similar to endoscopic treatment. ${ }^{35}$

Most authorities recommend that TIPSS be reserved for endoscopic or drug failures in the secondary prophylaxis of oesophageal variceal bleeding, citing the drawbacks of shunt insufficiency and hepatic encephalopathy in patients with TIPSS, as well as the absence of any clear cut survival benefit. ${ }^{13}$ These recommendations were made prior to the publication of the latest study, as discussed earlier. One trial should probably not change our views and practice dramatically but the data surely support the case for TIPSS to be seriously considered as a first line therapy in the prevention of rebleeding, at least in some patients. Most benefit may well be in patients with more advanced liver disease as Child's class A patients are unlikely to die from their bleed or rebleed and long term TIPSS patency cannot be guaranteed (see later). Further trials in this area are probably indicated, although the issue of TIPSS rescue will influence results. Efficient TIPSS rescue can only be achieved in centres where TIPSS insertion is undertaken regularly.

In the primary prevention of variceal bleeding, pharmacotherapy with non-selective beta blockers and nitrates is the mainstay of treatment. Variceal band ligation is also effective. ${ }^{14}$ Although no trials have been done with TIPSS, it is widely accepted that this procedure has no place in the

Abbreviation used in this review: TIPSS, transjugular intrahepatic portosystemic stent-shunt.

Table 1 Relation between study parameters and results

\begin{tabular}{|c|c|c|c|c|c|c|c|c|}
\hline \multirow[b]{2}{*}{ Study } & \multirow{2}{*}{$\begin{array}{l}\text { Time of } \\
\text { randomisation/ } \\
\text { primary therapy }\end{array}$} & \multirow{2}{*}{$\begin{array}{l}\text { Patients } \\
\text { randomised with } \\
\text { first bleed }(\%)\end{array}$} & \multirow{2}{*}{$\begin{array}{l}\text { Patients with } \\
\text { Child class } C \\
\text { cirrhosis (\%) }\end{array}$} & \multicolumn{2}{|c|}{ Rebleeding (\%) } & \multicolumn{2}{|c|}{ Mortality (\%) } & \multirow{2}{*}{$\begin{array}{l}\text { - Patients needing } \\
\text { "TIPSS rescue" }\end{array}$} \\
\hline & & & & $E S$ & TIPSS & $E S$ & TIPSS & \\
\hline $\begin{array}{l}\text { Cabrera and colleagues }{ }^{1} \text { (TIPSS, } \\
n=31 ; E S, n=32 \text { ) }\end{array}$ & $<3$ days & 68 & 10 & 51 & 23 & 16 & 19 & $28 \%$ (9 patients) \\
\hline $\begin{array}{l}\text { Rossle and colleagues }{ }^{2} \text { (TIPSS, } \\
n=61 ; E S, n=65)\end{array}$ & $<24$ hours & 39 & 18 & 45 & 15 & 13 & 12 & $14 \%$ (9 patients) \\
\hline $\begin{array}{l}\text { Cello and colleagues }{ }^{3} \text { (TIPSS, } \\
\mathrm{n}=24 ; \mathrm{ES}, \mathrm{n}=25)\end{array}$ & $<24$ hours & NS & NS & 48 & 12 & 16 & 12 & $24 \%$ (6 patients) \\
\hline $\begin{array}{l}\text { Sanyal and colleagues }{ }^{4} \text { (TIPSS, } \\
n=41 ; E S, n=39)\end{array}$ & ?9-11 days & 44 & 49 & 26 & 24 & 29 & 18 & $21 \%$ (8 patients) \\
\hline $\begin{array}{l}\text { Jalan and colleagues }{ }^{5} \text { (TIPSS, } \\
\mathrm{n}=41 ; \mathrm{ES}, \mathrm{n}=39)^{\star}\end{array}$ & 24 hours & 100 & 48 & 52 & 10 & 37 & 42 & $30 \%$ (8 patients) \\
\hline $\begin{array}{l}\text { Merli and colleagues }{ }^{6} \text { (TIPSS, } \\
n=38 ; E S, n=43 \text { ) }\end{array}$ & $\begin{array}{l}3 \text { strata; }<1 \text { week, } \\
1-6 \text { weeks, } 6 \text { weeks } \\
\text { to } 6 \text { months }\end{array}$ & 62 & 12 & 19 & 24 & 19 & 24 & $14 \%$ (6 patients) \\
\hline $\begin{array}{l}\text { Sauer and colleagues }^{7} \text { (TIPSS, } \\
n=42 ; E S, n=41)\end{array}$ & $1-3$ days & 100 & 24 & 57 & 23 & 31 & 33 & $12 \%$ (5 patients) \\
\hline $\begin{array}{l}\text { Garcia-Villareal and colleagues }^{8} \\
\quad(\text { TIPSS, } n=22 ; E S, n=24)\end{array}$ & 24 hours & 80 & 30 & 50 & 9 & 33 & 15 & $\begin{array}{l}5 \%(1 \text { patient, } 6 \\
\text { patients died before } \\
\text { rescue })\end{array}$ \\
\hline
\end{tabular}




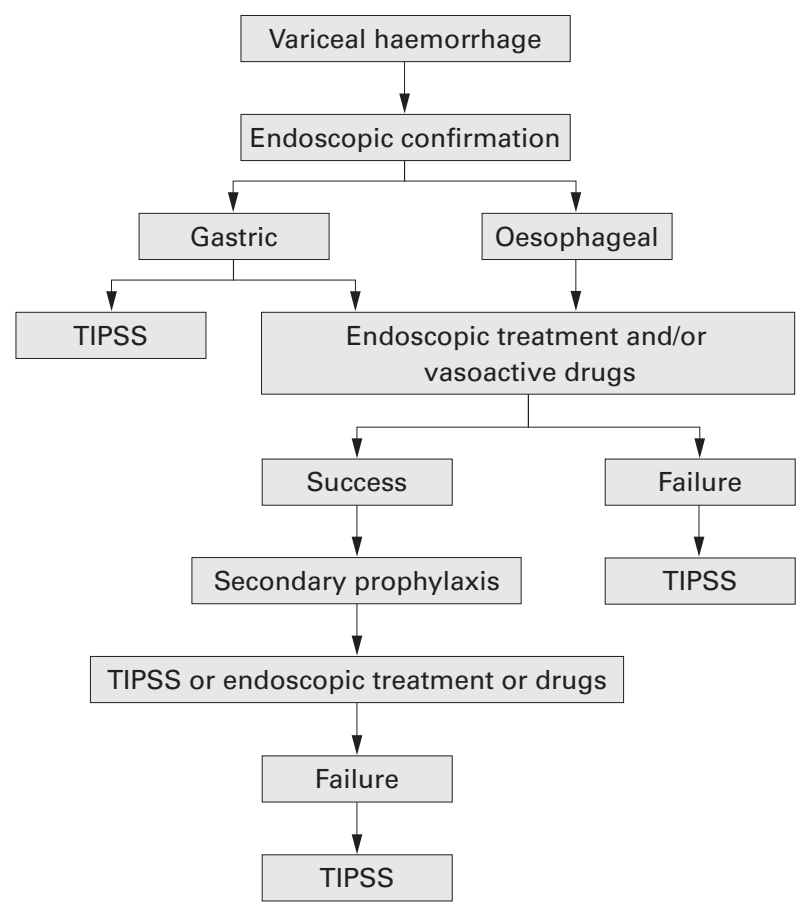

Figure 1 Role of transjugular intrahepatic portosystemic stent-shunts (TIPSS) in the management of variceal haemorrhage.

prevention of variceal bleeding. There are also no randomised studies looking at the role of TIPSS in acute variceal haemorrhage, in which endoscopic therapy has a proved track record. Nevertheless, in about $10 \%$ of patients an acute variceal bleed cannot be controlled despite two sessions of treatment within 24 hours. ${ }^{15}$ Available data show that a TIPSS can be placed in over $95 \%$ of cases, and when placed successfully, almost always controls the acute bleed. ${ }^{16}$ In a retrospective study of uncontrolled variceal bleeding, ${ }^{17}$ TIPSS was much better than oesophageal transection at lowering both mortality and rebleeding. Importantly, more patients were able to undergo TIPSS than surgery; this was thought to be the main reason for the improved survival. Further studies support this observation. ${ }^{18}{ }^{19}$ Present consensus recommends TIPSS as a rescue or "salvage" procedure for failed endoscopic therapy for acute variceal bleeding - that is, failure to achieve haemostasis after two endoscopic attempts. ${ }^{13}$

Compared with bleeding oesophageal varices, acute gastric variceal haemorrhage is particularly suited to treatment by TIPSS. Bleeding from gastric fundal varices is difficult to control and endoscopic injection of sclerosants is often unsatisfactory, with failure rates up to $50 \%$ depending on the sclerosant used. Butyl cyanoacrylate produces the best results but is accompanied by a complication rate of up to $40 \% .{ }^{20}$ Innovative techniques such as retrograde transvenous balloon obliteration of gastric varices, although around for the past 10 years, is not readily available and data exist only in the form of case reports and small series. ${ }^{21}$
The low frequency of gastric variceal bleeding (10\% of variceal bleeds) has partly been responsible for the paucity of data. Comparisons of gastric and oesophageal variceal haemorrhage treated with TIPSS were undertaken in two retrospective studies. ${ }^{22} 23$ These studies showed both the acute bleed and rebleeding to be as well controlled in gastric as in oesophageal varices. Many support the view that TIPSS should be used early in the management of acute fundal gastric variceal bleeding. ${ }^{13}$ Figure 1 illustrates the role of TIPSS in a suggested algorithm for managing variceal bleeding.

The second most studied indication is refractory ascites, and related complications such as hepatic hydrothorax and hepatorenal syndrome. Following TIPSS, beneficial responses in portal and systemic haemodynamic parameters, renal perfusion, renal plasma flow, sodium and water handling by the kidneys and plasma neurohormonal profile have been found.$^{24}$ Consequently, these would be expected to be translated into improved clinical outcomes, as indeed were reported in several series (table 2). However, randomised studies are lacking - only one study ${ }^{25}$ has been undertaken to look at TIPSS in the treatment of refractory ascites, comparing it with large volume paracentesis. Control was achieved in Child's class B patients but not in Child's class C patients. The latter in fact had a higher mortality when treated with TIPSS. This was, however, a small study of 25 patients. Overall, paracentesis is still viewed as the gold standard and the role of TIPSS in the treatment of refractory ascites needs to be evaluated further in larger clinical trials.

TIPSS has been used more successfully in the treatment of hepatic hydrothorax. Two studies (table 2) describing the use of TIPSS in 36 patients have shown complete control of hepatic hydrothorax in up to $60 \%$ and at least partial control in up to $80 \%$. The basis behind the observed clinical benefit in this group of patients, which seems to be better than the benefit observed in refractory ascites, is not clear. Alternative treatments are either unreliable (pleurodesis) or poorly accepted (repeated thoracocentesis), and TIPSS should be considered for control of this problem early in its management.

Hepatorenal syndrome is a complication of end stage liver disease. Not surprisingly, treatment options are limited and have been uniformly disappointing, although there have been some inroads made using plasma expanders in combination with vasoactive agents. ${ }^{34}$ Guevara and colleagues reported encouraging results in the treatment of hepatorenal syndrome using TIPSS. ${ }^{35}$ In our experience, however, hepatorenal syndrome often heralds the terminal phase of liver failure and the insertion of a TIPSS did not improve outcome. TIPSS cannot be recommended for hepatorenal syndrome outside the context of clinical trials.

TIPSS as an alternative to surgical shunting is effective in dealing with Budd-Chiari syndrome. ${ }^{36}$ TIPSS could be placed successfully in most patients and resulted in improvement of liver synthetic function, control of ascites, and where needed, bridged patients to liver transplanta-

Table 2 Summary of trials of transjugular intrahepatic portosystemic stent-shunt for refractory ascites and hepatic hydrothorax

\begin{tabular}{|c|c|c|c|c|c|}
\hline Study & Indication & $n$ & Response (complete) (\%) & 1 year survival (\%) & Prognostic factors for response \\
\hline Crenshaw and colleagues ${ }^{26}$ & Refractory ascites & 54 & $79(57)$ & 52 & NS \\
\hline Williams and colleagues ${ }^{27}$ & Refractory ascites & 15 & $53(40)$ & 54 & Renal insufficiency \\
\hline Rees and colleagues ${ }^{28}$ & Refractory ascites & 25 & 33 & 67 & NS \\
\hline Nazarian and colleagues ${ }^{29}$ & Refractory ascites & 50 & 62 & NS & Creatinine, bilirubin \\
\hline Forrest and colleagues ${ }^{30}$ & Refractory ascites & 18 & 27 & 50 & Creatinine, bilirubin \\
\hline Lebrec and colleagues ${ }^{25}$ & Refractory ascites & $13 / 12$ & 23 & 29 (2 years) & Child's class \\
\hline Ochs and colleagues ${ }^{32}$ & Refractory ascites & 50 & $92(74)$ & 55 & Nil \\
\hline Gordon and colleagues $^{33}$ & Hepatic hydrothorax & 24 & $79(58)$ & 57 & Nil \\
\hline Jeffries and colleagues ${ }^{34}$ & Hepatic hydrothorax & 12 & 58 & 58 & NS \\
\hline
\end{tabular}

NS, not stated. 


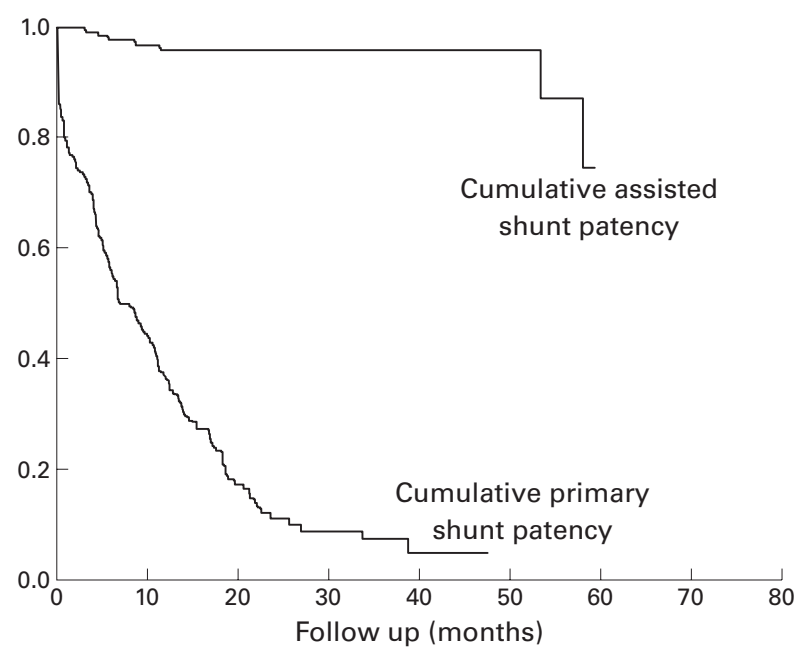

Figure 2 Kaplan-Meier plots of proportion of patients free of shunt insufficiency during follow up with (assisted patency) and without (primary patency) intervention.

tion. This is now increasingly the method of choice for shunting in Budd-Chiari syndrome.

\section{Complications}

The two main drawbacks of TIPSS are shunt insufficiency and development of hepatic encephalopathy. Shunt stenosis is expected in $60 \%$ of cases by 12 months. ${ }^{37}$ This comes about as a result of ingrowth of adjacent connective tissue into the stent (pseudointimal hyperplasia). Regular surveillance is therefore necessary to overcome this problem. Portography is the most reliable surveillance method. Doppler ultrasound, an attractive alternative, lacks the necessary sensitivity for it to be used alone for surveillance. In most cases, intervention to the insufficient shunt in the forms of balloon angioplasty, shunt extension or insertion of parallel stent re-establishes good function. A programme of regular shunt surveillance, with intervention as appropriate, can achieve long term patency rates of over $90 \%$ at four years (fig 2). A further innovation is the development of covered stents, ${ }^{38}$ which may have the potential to reduce the severity of pseudointimal hyperplasia, thereby retarding shunt stenosis. This would be an important question to answer in future studies.

Hepatic encephalopathy, a function of portosystemic shunting and poor liver function, has been shown in several studies (table 3) to occur at an increased frequency following TIPSS. Encephalopathy has been found in around 35\% of patients with TIPSS at some point in their follow up compared with a figure of $20 \%$ in patients managed endoscopically. Spontaneous hepatic encephalopathy prior to TIPSS is the most consistent independent prognostic variable predicting its development. Prior hepatic encephalopathy should therefore be a relative contraindication for TIPSS; other treatment options should be explored first and TIPSS should be used only as a last resort - for example, in failed endoscopic treatment of a life threatening bleed. Most published studies do not provide further information beyond incidence figures of encephalopathy. Details pertaining to the natural history and characteristics of individual episodes would be very important to give us an idea of its clinical importance. Available data ${ }^{40}{ }^{43}$ suggest that most episodes are short lived, do not require admission to hospital, and are amenable to simple medical measures such as lactulose and avoidance of precipitants. Furthermore, new onset encephalopathy is clustered around the first month after TIPSS insertion and improvement of neurological status was observed in a significant number of patients during follow up. Chronic spontaneous encephalopathy develops in about $10 \%$ and is sufficiently debilitating to require closure of the shunt in most of the patients who develop this problem. This can be done using reducing stents, LGV filters or coils, but when these measures fail, suggesting that deteriorating liver function is the cause of the encephalopathy, liver transplantation should be considered. Putting these issues into perspective, it seems that post-TIPSS encephalopathy as a problem may have been overstated. Studies specifically looking at the natural history of post-TIPSS encephalopathy and its impact on overall quality of life are needed to answer uncertainties that still exist in this area.

\section{Conclusion}

TIPSS is currently used with variable enthusiasm. In the UK, continental Europe and the USA, the use of TIPSS seems to be concentrated in a few centres where large numbers are performed. The drawbacks mentioned earlier have undoubtedly disappointed the many who expected more, although the backlash seems to have been excessive, leading to the underuse of this technique and perhaps the failure to realise its potential. Furthermore, the limited availability of this procedure has not helped it to be applied more widely. This was inevitable as TIPSS is one of the more demanding interventional radiology procedures requiring the service of a skilled radiologist who has scaled the steep learning curve, which can only come about in a specialist unit. A rational approach would be for the practising doctor to recognise the indications and drawbacks of this procedure and for the appropriate cases to be referred to the specialist units where TIPSS insertion is done routinely. Finally, our practice should neither be dictated by "TIPSS sceptics" nor should it be influenced by "TIPSS enthusiasts", but rather be evidence-based. In the past 10 years TIPSS research has provided a large body of evidence which will hopefully be added upon in the coming decade.

R JALAN
H F LUI
D N REDHEAD
P C HAYES
Liver Unit,
Department of Medicine and Department of Radiology,
Royal Infirmary of Edinburgh,
1 Lauriston Place,
Edinburgh EH3 $9 \mathrm{YW} U \mathrm{UK}$

Correspondence to: Professor Hayes

Table 3 Post-transjugular intrahepatic portosystemic stent-shunt (TIPSS) hepatic encephalopathy

\begin{tabular}{|c|c|c|c|c|c|}
\hline Study & $n$ (with TIPSS) & Indication for TIPSS & $\begin{array}{l}\text { Patients with Child class } \\
\text { C cirrhosis (\%) }\end{array}$ & $\begin{array}{l}\text { New or worsened hepatic } \\
\text { encephalopathy (\%) }\end{array}$ & $\begin{array}{l}\text { Chronic hepatic } \\
\text { encephalopathy (\%) }\end{array}$ \\
\hline Martin and colleagues ${ }^{39}$ & 45 & Variceal bleed & 20 & 43 & 20 \\
\hline Rossle and colleagues ${ }^{16}$ & 93 & Variceal bleed & 22 & 16 & 7 \\
\hline Sanyal and colleagues ${ }^{40}$ & 30 & Variceal bleed & 29 & 47 & 3 \\
\hline Somberg and colleagues ${ }^{41}$ & 77 & Variceal bleed, refractory ascites & 29 & 23 & 5 \\
\hline Jalan and colleagues ${ }^{42}$ & 68 & Variceal bleed & 31 & 13 & NS \\
\hline Coldwell and colleagues ${ }^{43}$ & 96 & Variceal bleed & 35 & 25 & 7 \\
\hline Ochs and colleagues ${ }^{26}$ & 50 & Refractory ascites & 64 & 44 & 16 \\
\hline
\end{tabular}

NS, not stated. 
1 Cabrera J, Maynar M, Granados R, et al. Transjugular intrahepatic portosystemic shunt versus sclerotherapy in the elective treatment of

2 Rossle M, Deibert P, Haag K, et al. Randomised trial of transjugularintrahepatic-portosystemic shunt versus endoscopy plus propranolol for the prevention of variceal rebleeding. Lancet 1997;349:1043-9.

3 Cello JP, Ring EJ, Olcott EW, et al. Endoscopic sclerotherapy compared with percutaneous transjugular intrahepatic portosystemic shunt after initial sclerotherapy in patients with acute variceal haemorrhage: A randomized controlled trial. Ann Intern Med 1997;126:858-65.

4 Sanyal AJ, Freedman AM, Luketic VA, et al. Transjugular intrahepatic portosystemic shunts compared with endoscopic sclerotherapy for the preven-
tion of recurrent variceal haemorrhage: a randomized controlled trial. Ann Intern Med 1997;126:849-57.

5 Jalan R, Forrest EH, Stanley AJ, et al. A randomised trial comparing transjugular intrahepatic portosystemic stent-shunt with variceal band ligation in the prevention of rebleeding from oesophageal varices. Hepatology 1997; 26:1115-22.

6 Sauer P, Theilmann L, Stremmel W, et al. Transjugular intrahepatic portosystemic stent shunt versus sclerotherapy plus propranolol for variceal systemic stent shunt versus sclerotherapy plus
rebleeding. Gastroenterology 1997;113:1623-31.

7 Merli M, Salerno F, Riggio O, et al. Transjugular intrahepatic portosystemic shunt versus endoscopic sclerotherapy for the prevent of variceal bleeding in cirrhosis: a randomised multicenter trial. Gruppo Italiano Studio TIPS (G.I.S.T). Hepatology 1998;27:48-53.

8 Garcia-Villarreal L, Martinez-Lagares F, Sierra A, et al. Transjugular intrahepatic portosystemic shunt versus endoscopic sclerotherapy for the prevention of variceal rebleeding after recent variceal hemorrhage. Hepatology 1999;29:27-32.

9 Groupe d'Etudes des Anastamoses Intr-Hepatiques (Toulouse BLNCPF). TIPS vs sclerotherapy + propranolol in the prevention of variceal rebleeding: preliminary results of a multicenter randomized trial [abstract]. Hepatology 1995;22(suppl):229A.

10 Pomier-Layrargues G, Dufresne MP, Bui B, et al. TIPS vs endoscopic variceal ligation in the prevention of variceal rebleeding in cirrhotic patients: a comparative randomized clinical trial (interim analysis) [abstract]. Hepatology 1997;26(suppl):137A.

11 Sauer P, Benz C, Theilmann L, et al. Transjugular intrahepatic portosystemic stent shunt (TIPS) vs endoscopic banding in the prevention portosystemic stent shunt (TIPS) vs endoscopic banding in the prevention enterology 1998;114:A1334.

12 Papatheodoridis GV, Goulis J, Leandro G, et al. Transjugular intrahepatic portosystemic shunt compared with endoscopic treatment for prevention of variceal rebleeding: A meta-analysis. F Hepatol 1999;30:612-22

13 Grace ND, Groszmann RJ, Garcia-Tsao G, et al. Portal hypertension and variceal bleeding: an AASLD single topic symposium. If Hepatol 1998;28:868-80.

14 Sarin SK, Lamba GS, Kumar M, et al. Comparison of endoscopic ligation and propranolol for the primary prevention of variceal bleeding. $N$ Engl $\mathcal{F}$ Med 1999;340:988-93.

15 Burroughs AK, Hamilton G, Phillips A, et al. A comparison of sclerotherapy with staple transection of the esophagus for the emergency control of bleeding from esophageal varices. N Engl f Med 1989;321:857-62.

16 Rossle M, Haag K, Ochs A, et al. The transjugular intrahepatic portosystemic stent-shunt procedure for variceal bleeding. $N$ Engl f Med 994:330:165-71.

17 Jalan R, John TG, Redhead DN, et al. A comparative study of the transjugular intrahepatic portosystemic stent-shunt (TIPSS) and oesophageal transection in uncontrolled variceal haemorrhage. Am $\mathcal{f}$ Gastroenterol geal transection in

18 McCormick PA, Dick R, Panagou EB, et al. Emergency transjugular intrahepatic portasystemic stent shunting as salvage treatment for uncontrolled variceal bleeding. Br $\mathcal{F}$ Surg 1994;81:1324.

19 Sanyal AJ, Freedman AM, Luketic VA, et al. Transjugular intrahepatic portosystemic shunts for patients with active variceal hemorrhage unresponsive to sclerotherapy. Gastroenterology 1996;111:138-46.

20 Oho K, Iwao T, Sumino M, et al. Ethanolamine oleate versus butyl cyanoacrylate for bleeding gastric varices: a non-randomized study. Endoscopy $1995 ; 27: 349-54$.

21 Hirota S, Matsumoto S, Tomita $\mathrm{M}$, et al. Retrograde transvenous obliteration of gastric varices. Radiology 1999;211:349-56.
22 Chau TN, Patch D, Chan YW, et al. Salvage transjugular intrahepatic portosystemic shunts: gastric fundal compared with esophageal variceal bleeding. Gastroenterology 1998;114:981-7.

23 Stanley AJ, Jalan R, Ireland HM, et al. A comparison between gastric and oesophageal variceal haemorrhage treated with transjugular intrahepatic portosystemic stent shunt (TIPSS). Aliment Pharmacol Ther 1997;11:1716.

24 Wong F, Sniderman K, Liu P, et al. Transjugular intrahepatic portosystemic stent shunt: effects on hemodynamics and sodium homeostasis in cirrhosis and refractory ascites. Ann Intern Med 1995;122:816-22.

25 Lebrec D, Giuily N, Hadengue A, et al. Transjugular intrahepatic portosystemic stent shunts: comparison with paracentesis in patients with cirrhosi and refractory ascites. a randomised trial. F Hepatol 1996;25:135-44.

26 Ochs A, Rossle M, Haag K, et al. The transjugular intrahepatic portosystemic stent-shunt procedure for refractory ascites. $N$ Engl F Med 1995;332:1192-7.

27 Crenshaw WB, Gordon FD, McEniff NJ, et al. Severe ascites: efficacy of the transjugular intrahepatic portosystemic shunt in treatment. Radiology 1996;200:185-92.

28 Forrest EH, Stanley AJ, Redhead DN, et al. Clinical response after transjugular intrahepatic portosystemic stent shunt insertion for refractory ascites in cirrhosis. Aliment Pharmacol Ther 1996;10:801-6.

29 Rees CJ, Rose JD, Record CO, et al. Transjugular intrahepatic portosystemic shunt: a limited role in refractory ascites. Eur $\mathcal{F}$ Gastroenterol Hepatol 1997; 9:969-73.

30 Nazarian GK, Bjarnason H, Dietz CA Jr, et al. Refractory ascites: midterm results of treatment with a transjugular intrahepatic portosystemic shunt. Radiology 1997;205:173-80.

31 Williams DB, Waugh R, Selby W. Transjugular intrahepatic portosystemic shunt (TIPS) for the treatment of refractory ascites. Aust NZ 7 Med 1998; 28:620-6.

32 Gordon FD, Anastopoulos HT, Crenshaw W, et al. The successful treatment of symptomatic, refractory hepatic hydrothorax with transjugular intrahepatic portosystemic shunt. Hepatology 1997;25:1366-9.

33 Jeffries MA, Kazanjian S, Wilson M, et al. Transjugular intrahepatic portosystemic shunts and liver transplantation in patients with refractory hepatic hydrothorax. Liver Transplant Surg 1998;4:416-23.

34 Guevara M, Gines P, Fernandez-Esparrach G, et al. Reversibility of hepatorenal syndrome by prolonged administration of ornipressin and plasma volume expansion. Hepatology 1998;27:35-41.

35 Guevara M, Gines P, Bandi JC, et al. Transjugular intrahepatic portosystemic shunt in hepatorenal syndrome:effects on renal function and vasoactive systems. Hepatology 1998;28:416-22.

36 Blum U, Rossle M, Haag K, et al. Budd-Chiari syndrome: technical, hemodynamic, and clinical results of treatment with transjugular intrahepatic portosystemic shunt. Radiology 1995;197:805-11.

37 Lind CD, Malisch TW, Chong WK, et al. Incidence of shunt occlusion or stenosis following transjugular intrahepatic portosystemic shunt placement. Gastroenterology 1994;106:1277-83.

38 Haskal ZJ, Davis A, McAllister A, et al. PTFE-encapsulated endovascular stent-graft for transjugular intrahepatic portosystemic shunts: experimental evaluation. Radiology 1997;205:682-8.

39 Martin M, Zajko AB, Orons PD, et al. Transjugular intrahepatic portosystemic shunt in the management of variceal bleeding: indications and clinical results. Surgery 1993;114:719-26.

40 Sanyal AJ, Freedman AM, Shiffman ML, et al. Portosystemic encephalopathy after transjugular intrahepatic portosystemic shunt: results of a prospective controlled study. Hepatology 1994;20:46-55.

41 Somberg KA, Riegler JL, LaBerge JM, et al. Hepatic encephalopathy after transjugular intrahepatic portosystemic shunts: incidence and risk factors. Am f Gastroenterol 1995;90:549-55.

42 Jalan R, Elton RA, Redhead DN, et al. Analysis of prognostic variables in the prediction of mortality, shunt failure, variceal rebleeding and encephalopathy following the transjugular intrahepatic portosystemic stent-shunt for variceal haemorrhage. F Hepatol 1995;23:123-8.

43 Coldwell DM, Ring EJ, Rees CR, et al. Multicenter investigation of the role of transjugular intrahepatic portosystemic shunt in management of portal hypertension. Radiology 1995;196:335-40. 